\title{
Haiti emerging from chaos to face health care crisis
}

As Haiti emerges from the chaos of its recent unrest to an uncertain and fragile calm, the international medical community is struggling to deal with the country's health care crisis.

Considered to be the poorest nation in the Western Hemisphere, with about $80 \%$ of its population living below the poverty line, Haiti is also stricken with a "dying" public health care system, says French surgeon Dr. Peter Tarabula, medical coordinator of the International Committee of the Red Cross (ICRC) delegation in the capital, Port-au-Prince.

A 2003 Red Cross study indicates there is fewer than 1 hospital bed for every $1000 \mathrm{pa}-$ tients throughout Haiti and, according to Tarabula, 209 surgical beds for the 6 million people living outside Port-auPrince.

Only about $60 \%$ of Haiti's 8 million residents have access to any form of health care services, according to the Pan American Health Organization (PAHO). Most people rely on public facilities where they must pay a minimal fee based on income and family size.

Recent events have worsened this already bleak situation, said Tarabula in an interview from the capital. Amid the upheaval, Haiti's 700-bed state university hospital, the largest public medical facility in Portau-Prince, had no doctors or nurses on duty.

"Medical and administrative staff were not coming in during the peak of the fighting for fear of violence spilling into the hospital," said Quebec nurse Élisabeth Carrier, who is overseeing the ICRC mission's dis$\exists$ tribution of 32000 kilograms of medical supplies and equipment to hospitals and clinics throughout Haiti.

PAHO reports that although some private hospitals are slowly restoring services, the crisis has had a major impact on public hospitals. It issues daily radio bulletins advising residents which hospitals are operating. In early March, the UN made an appeal for urgent aid.

Most Haitians also lack clean drinking water, proper sewage systems and reliable electricity. The average life expectancy at birth is 50 years and the infant mortality rate is 79 per 1000 live births. The mortality rate among children under 5 is 123 per 1000 live births.

Poor sanitation and hygiene, coupled with inadequate nutrition, have contributed to a high incidence of physical challenges, ranging from congenital deformities and amputations to stroke-related paralysis and head and spinal cord injuries, explains Dr. Colleen O'Connell, a Fredericton physiatrist who volunteers with Healing Hands for Haiti. The 6-year-old, USbased non-profit organization brings rehabilitation medicine and training to the poor Caribbean nation. There's no way of knowing what the prevalence is precisely, because of the paucity of data.

In January, O'Connell spent 2 weeks in Port-au-Prince as leader of a 29-member Canadian Healing Hands health care team (the only one outside the US) that ran daily medical clinics for as many as 80 adults and children, trained Haitian students, caregivers and technicians in rehabilitation medicine, and brought in nearly $2000 \mathrm{~kg}$ of medical equipment, tools and supplies, including wheelchairs, antibiotics and components for prostheses and orthoses.

O'Connell explained that during visits to 7 orphanages each of which can hold as many as 100 children - her group likely saw the "strongest" of those with cerebral palsy, "because the weaker and more frail ones would have died." There are about 60 orphanages in Port-au-Prince alone, many run by religious organizations.
Many of those orphaned without physical disabilities have lost one or both of their parents to AIDS. Haiti has one of the highest rates of HIV/AIDS infection outside of Africa; an estimated 250000 are living with the disease, according to WHO.

In 2001, 30000 Haitians died from AIDS: twice the number who succumbed to the disease in the US. The country's Global Fund-supported HIV/AIDS programs managed to serve their communities uninterrupted thanks to some preemptive disbursements of funds and medications ahead of the

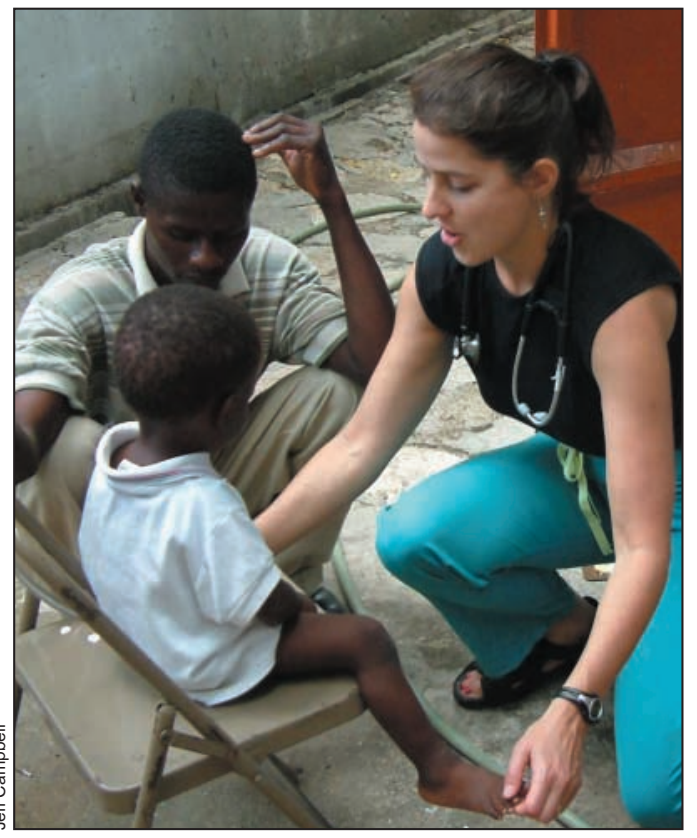

Dr. Colleen O'Connell: "We need to help them establish a sustainable health care system."

worst crisis. The fund has allocated US\$66.9 million over 5 years to the programs.

Having been to Haiti 3 times over the past year, O'Connell plans to soon return there with another Canadian contingent.

"Band-Aid solutions are fine for now," she explained. "But if Haitians are going to have a better future, we need to help them establish a sustainable healthcare system." - Christopher Guly, Carp, Ont. 